\title{
Short communication: Variable number of tandem repeat polymorphisms in DGAT1 gene of buffaloes (Bubalus bubalis) is associated with milk constituents
}

\author{
D. F. Cardoso, ${ }^{*}$ G. F. P. de Souza, ${ }^{*}$ R. R. Aspilcueta-Borquis, ${ }^{*}$ F. R. Araujo Neto, $\dagger$ G. M. F. de Camargo, ${ }^{*}$ \\ N. A. Hurtado-Lugo, ${ }^{\star}$ D. C. B. Scalez, ${ }^{*}$ A. C. de Freitas, ${ }^{*}$ L. G. Albuquerque, ${ }^{*}$ and H. Tonhati ${ }^{* 1}$ \\ *Departamento de Zootecnia, Faculdade de Ciências Agrárias e Veterinárias, Universidade Estadual Paulista (UNESP), Jaboticabal, \\ SP 14884-900, Brazil \\ †Instituto Federal Goiano-Campus Rio Verde, GO 75901-970, Rio Verde, Brazil
}

\begin{abstract}
The diacylglycerol-O-transferase 1 gene is a positional and functional candidate for milk composition traits. The objective of this study was to evaluate the segregation of the variable number of tandem repeat polymorphisms in the regulatory region of diacylglycerol-O-transferase 1 gene in a water buffalo herd, and to assess the association of this mutation with milk production traits. For this purpose, 196 Murrah buffalo cows were genotyped by PCR. The association of the marker with total milk, fat, and protein yields at 305 $\mathrm{d}$ of lactation, milk fat and protein percentage, and somatic cell scores were evaluated by single-trait analyses using a generalized mixed model. Two segregating alleles were identified in the population. The allele with 2 repeats affected fat percentage favorably. The present results suggest that this polymorphism is an interesting marker to include in the genetic evaluation of buffaloes. Key words: fat percentage, molecular marker, Murrah, variable number of tandem repeats (VNTR)
\end{abstract}

\section{Short Communication}

Microsomal diacylglycerol acyltransferase enzyme plays a key role in the energy storage of eukaryotic organisms, catalyzing the final step of triglyceride synthesis from diacylglycerol and FA-CoA (Cases et al., 1998). This enzyme is expressed in practically all tissues (Farese et al., 2000). Its importance increases during physiological stages that require greater mobilization of body energy, such as lactation.

In cattle, the diacylglycerol-O-transferase1 gene (DGAT1) is located in a region of chromosome 14 where QTL for economically important milk production traits, particularly fat content, have been detected (Heyen et

Received August 11, 2014.

Accepted January 14, 2015.

${ }^{1}$ Corresponding author: tonhati@fcav.unesp.br al., 1999; Riquet et al., 1999). According to Kühn et al. (2004), a variable number of tandem repeat (VNTR) polymorphisms, with 5'-AGGCCCCGCCCTCCCCGG-3' sequence in the $5^{\prime}$ untranslated region of the $D G A T 1$, is a putative causal mutation that explains the QTL in BTA14. This DGAT1-VNTR contains a binding site (CCCGCC) of specificity protein 1 (Sp1), a transcription factor that assists the RNA polymerase to find the starting site for the mRNA synthesis (Courey and Tijan, 1988). It is hypothesized that alleles with a larger number of repeats of the 18-nucleotide sequence increase the expression of DGAT1 in the mammary gland, resulting in higher milk fat production.

The identification of potential genes that have a great effect on traits of interest is important for water buffaloes. Still, few have been identified, as it is more difficult to map QTL in buffaloes compared with other species, such as Bos taurus. One reason is that a publically available genome is not available for buffalo. However, the physiological effect of the DGAT1 gene on lactation means that screening for mutations of this gene is of interest in any mammalian species where milk production is an important selection criterion. Although Yuan et al. (2007) described variability in the number of binding sites of transcription factor Sp1 generated by the DGAT1-VNTR polymorphism in Murrah, Nili-Ravi, and crossbred buffaloes in China, no association studies have been reported so far for milk traits in water buffalo.

The objective of the present study was to evaluate the segregation of the VNTR polymorphism in the $5^{\prime}$ untranslated regulatory region of the DGAT1 gene in a water buffalo population, as well as the association of this mutation with the main traits used to select for milk production. Animal Care and Use Committee approval was not requested before the execution of this work because the data were obtained from existing databases of the dairy buffalo milk-recording program of the Universidade Estadual Paulista (UNESP) and from already stocked biological material. 
Our study used biological material and phenotypic records from 196 first-lactation Murrah buffalo cows aged 2 to $4 \mathrm{yr}$, daughters of 12 sires (minimum 5 and maximum 20 daughters per sire), reared in the same farm in Taipu, Rio Grande do Norte, Brazil. The contemporary groups were the combinations of calving year and calving season. The animal selection for genotyping considered the contemporary groups that contained at least 3 animals.

Buffalo DNA was extracted from hair follicles by the phenol-chloroform-isoamyl alcohol method. The PCR technique used the following primers pair: $D G A T 1_{\text {up }}$ 5'-ACCTTGACCTTTTCCCTCGT-3' and DGAT1 $1_{\mathrm{dn}}$ 5'-GACTGTGAAGGCACCAATCA-3'. The primers were designed based on the buffalo sequence deposited in the GenBank under the accession number AY999090 (Yuan et al., 2007). After PCR assays, a 5- $\mu \mathrm{L}$ aliquot of the PCR products underwent a 4-h electrophoresis on low-melting $4 \%$ agarose gel and the genotype of each animal was obtained from the migration pattern observed in the gels. Two samples of each migration pattern identified in our study were sequenced using the technique described by Sanger et al. (1977). The sequences were visualized with the Codon Code Aligner software (available at http://www.codoncode. com/aligner/download.htm) to determine the number of repeats in each migration pattern observed in gel.

Two fragments of different sizes were observed in the gel. The smaller and larger fragments were 193 and 211 bp long and corresponded to alleles $1 \mathrm{R}$ and $2 \mathrm{R}$, respectively. Animals carrying $1 \mathrm{R}$ and $2 \mathrm{R}$ alleles shave 3 and 4 Sp1-binding sites, respectively, in the promoter region of the DGAT1 gene. Although the VNTR observed in our study consists of the same 18-nucleotide sequence described for cattle by Kühn et al. (2004), no studies have reported the existence of $1 \mathrm{R}$ allele in other species. The $2 \mathrm{R}$ allele has been described by Gautier et al. (2007) with frequencies of less than 0.01 in Normande and Montbéliarde cattle. The frequencies we observed were 0.62 and 0.38 for alleles $1 R$ and $2 R$, respectively. The genotype frequencies were $0.37,0.13$, and 0.50 for the homozygous $1 \mathrm{R} / 1 \mathrm{R}$ and $2 \mathrm{R} / 2 \mathrm{R}$ and heterozygous $1 \mathrm{R} / 2 \mathrm{R}$ genotypes, respectively, in agreement with the expected frequencies at Hardy-Weinberg equilibrium $(P<0.05)$.

The association analysis used the following phenotypic records: accumulated 305-d milk, fat, and protein yields, fat $(\mathbf{\%} \mathbf{F})$ and protein percentage, and SCS. Total yields were estimated from monthly records adjusted to 305 lactation days. Fat and protein percentages were obtained based on the monthly average of lactation test-day records according to Tonhati et al. (2000). The average test-day SCC was transformed into SCS using the equation proposed by Dabdoub and Shook (1984):
$\mathrm{SCS}=\left[\log _{2}(\mathrm{SCC} / 100,000)\right]+3$. The association between the DGAT1-VNTR marker and each studied trait was determined by univariate analysis using the following statistical model with the R software MASS (Venables and Ripley, 2002):

$$
y_{i j k l}=\mu+C G_{i}+A C_{j}+A C_{j}^{2}+M_{k}+A_{l}+e_{i j k l},
$$

where $y_{i j k l}$ corresponds to 305 -d milk, fat, and protein yields, $\% \mathrm{~F}$, protein percentage, and SCS measured in the $i j k l t h$ animal; $\mu$ is the mean of each trait in the population; $C G_{i}$ is the fixed effect of the $i$ th contemporary group $(1 \ldots 18) ; A C_{j}$ is the age of the $j$ th cow at calving, which was included in the model as a linear and quadratic covariate; $M_{k}$ is the fixed effect of the $k$ th genotype of the DGAT1-VNTR marker (1R1R, 1R2R and $2 \mathrm{R} 2 \mathrm{R}) ; A_{l}$ is the additive genetic random effect of animal; and $e_{i j k l}$ is the residual random effect associated with observation $y_{i j k l}$.

The $P$-value threshold for significance based on Bonferroni correction $\left(\alpha=0.05 / \mathrm{N}_{\text {traits }}\right.$, where $\mathrm{N}_{\text {traits }}=$ number of traits, 6) was used to keep reasonable probability values for type I errors. The allele substitution and dominance effects were included in the model as covariates when the association between the polymorphism and trait $(P<0.008)$ was observed. The substitution allele effect was estimated by linear regression of phenotypic values on the number of the $2 \mathrm{R}$ allele in each genotype $(0,1$, and 2$)$. Dominance effects were estimated by linear regression of the phenotypic values on an indicator variable taking the value 0 to homozygotes and 1 to heterozygotes genotypes.

The percentage of the additive genetic variance of the $\% \mathrm{~F}$ trait accounted by the DGAT1-VNTR was estimated according to the following equation:

$$
\% V_{\alpha}=100\left(\frac{2 p(1-p) \hat{\alpha}^{2}}{\sigma_{a}^{2}}\right),
$$

where $p$ is the frequency of $2 \mathrm{R}$ allele estimated across the population; $\hat{\alpha}^{2}$ is the square of estimated allele substitution effect of the DGAT1-VNTR on the $\% \mathrm{~F}$ trait; and $\sigma_{a}^{2}$ is the additive genetic variance for the $\% \mathrm{~F}$ estimated by REML in the Wombat software (Meyer, 2007) using the complete database of the dairy buffalo milkrecording program (Aspilcueta-Borquis et al., 2010).

The DGAT1-VNTR marker was found to be associated with $\% \mathrm{~F}$ considering the stringent significance limit established by Bonferroni correction $(P<0.008$; Table 1). Furthermore, it explained about $32 \%$ of the additive genetic variance estimates to this trait using the complete database of the dairy buffalo milk-record- 
Table 1. Mean ( \pm SE) milk yield (MY305), fat yield (FY305), and protein yield (PY305) at $305 \mathrm{~d}$, fat percentage $(\% \mathrm{~F})$, protein percentage $(\% \mathrm{P})$, and SCS according to genotype of the diacylglycerol-O-transferase 1 (DGAT1)-VNTR ${ }^{1}$ marker

\begin{tabular}{lcccc}
\hline & \multicolumn{3}{c}{ Genotype } & \\
\cline { 2 - 4 } Trait & $1 \mathrm{R} / 1 \mathrm{R}$ & $1 \mathrm{R} / 2 \mathrm{R}$ & $2 \mathrm{R} / 2 \mathrm{R}$ & $P$-value \\
\hline MY305 $(\mathrm{kg})$ & $1,737 \pm 330$ & $1,793 \pm 287.8$ & $1,838 \pm 237.8$ & 0.534 \\
FY305 $(\mathrm{kg})$ & $115.2 \pm 33.8$ & $118.2 \pm 30.9$ & $128.9 \pm 31.9$ & 0.472 \\
PY305 $(\mathrm{kg})$ & $74.7 \pm 24.7$ & $77.6 \pm 23.1$ & $81.2 \pm 27.7$ & 0.490 \\
\% & $6.18 \pm 0.07^{\mathrm{b}}$ & $6.62 \pm 0.07^{\mathrm{b}}$ & $7.66 \pm 0.07^{\mathrm{a}}$ & 0.003 \\
\%P & $4.12 \pm 0.03$ & $4.41 \pm 0.03$ & $4.73 \pm 0.03$ & 0.041 \\
SCS & $5.46 \pm 0.04$ & $5.57 \pm 0.04$ & $5.34 \pm 0.04$ & 0.782 \\
\hline
\end{tabular}

${ }^{\mathrm{a}, \mathrm{b}}$ Means in the same row with different superscripts differ by Tukey test $(P<0.05)$.

${ }^{1}$ For DGAT1, 2 fragments of different sizes were observed: 193 and $211 \mathrm{bp}$, corresponding to alleles $1 \mathrm{R}$ and 2R, respectively. Animals carrying $1 \mathrm{R}$ and $2 \mathrm{R}$ alleles have 3 and 4 Sp1-binding sites, respectively, in the promoter region of the DGAT1 gene. VNTR = variable number of tandem repeats.

ing program, whose value is $0.26 \pm 0.06$ (AspilcuetaBorquis et al., 2010). Allele 2R was favorably correlated with $\% \mathrm{~F}$. The allele substitution effect on $\% \mathrm{~F}$ was 0.41 $\pm 0.17(P<0.01)$. The dominance deviation estimated for $\% \mathrm{~F}$ was $0.62 \pm 0.02(P>0.05)$. These results agree with studies in cattle where alleles containing a larger number of Sp1-binding sites in the promoter region of the DGAT1 gene caused an increase in milk fat percentage. Kühn et al. (2004) and Kuehn et al. (2007) observed allele substitution effect on milk fat percentage considering the substitution of any allele by the allele with 7 repeats.

According to Seno et al. (2006, 2007), the components of buffalo milk have a positive economic value in marketing systems with compensation policies based either on milk composition, or farm intention to commercialize value-added products such as cheese. Selection criteria maximizing the proportion of milk components (such as fat and protein) will probably increase the frequency of the $2 \mathrm{R}$ allele in the buffalo population, even if limited to traditional selection methods. However, it is worth noting that genotyping of animals at a single locus is an inexpensive and justifiable practice, as directional selection for a specific trait is of high economic importance.

According to Glazier et al. (2002), the variance of complex traits has been shown to be more commonly influenced by variations in noncoding regions involved in gene regulation rather than coding regions. The results of the present study indicate another case in which polymorphism in regulatory regions influences the variance of a complex trait. Although the results of our study are promising, the study should be repeated in another larger population to validate the influence of the variant in buffalo. Gene expression could also be studied to confirm the hypothesis that the variant affects the expression. The present results suggest that VNTR polymorphisms in the promoter region of the
$D G A T 1$ gene influence the milk fat percentage of dairy buffaloes.

\section{ACKNOWLEDGMENTS}

The authors thank the Tapuio farm, Taipu, Rio Grande do Norte, Brazil, for providing the data and biological material used in this study, and are grateful for the financial support offered by grant 2011/22163-3 from Fundacao de Amparo a Pesquisa do Estado de Sao Paulo (FAPESP, São Paulo, SP, Brazil).

\section{REFERENCES}

Aspilcueta-Borquis, R. R., F. R. Araújo Neto, F. Baldi, A. B. Bignardi, L. G. Albuquerque, and H. Tonhati. 2010. Genetic parameters for buffalo milk yield and milk quality traits using Bayesian inference. J. Dairy Sci. 93:2195-2201.

Cases, S., S. J. Smith, Y. Zheng, H. M. Myers, S. R. Lear, E. Sande, S. Novak, C. Collins, C. B. Welch, A. J. Lusis, and S. K. Erickson. 1998. Identification of a gene encoding an acyl CoA diacylglycerolacyltransferase, a key enzyme in triacylglycerol synthesis. Proc. Natl. Acad. Sci. USA 95:13018-13023.

Courey, A. J., and R. Tjian. 1988. Analysis of Sp1 in vivo reveals multiple transcriptional domains, including a novel glutamine-rich activation motif. Cell 55:887-898.

Dabdoub, S. A. M., and G. E. Shook. 1994. Phenotypic relations among milk yield, somatic count cells, and mastitis. J. Dairy Sci 67(Suppl. 1):163-164. (Abstr.)

Farese, R. V., Jr., S. Cases, and S. J. Smith. 2000. Triglyceride synthesis: Insights from the cloning of diacylglycerolacyltransferase. Curr. Opin. Lipidol. 11:229-234.

Gautier, M., A. Capitan, S. Fritz, A. Eggen, D. Boichard, and T Druet. 2007. Characterization of the DGAT1K232A and variable number of tandem repeat polymorphisms in French dairy cattle. J. Dairy Sci. 90:2980-2988.

Glazier, A. M., J. H. Nadeau, and T. J. Aitman. 2002. Finding genes that underlie complex traits. Science 298:2345-2349.

Heyen, D. W., J. I. Weller, M. Ron, M. Band, J. E. Beever, E. Feldmesser, Y. Da, G. R. Wiggans, P. M. VanRaden, and H. A. Lewin. 1999. A genome scan for QTL influencing milk production and health traits in dairy cattle. Physiol. Genomics 1:165-175.

Kuehn, C., C. Edel, R. Weikard, and G. Thaller. 2007. Dominance and parent-of-origin effects of coding and non-coding alleles at the acylCoA-diacylglycerol-acyltransferase (DGAT1) gene on milk 
production traits in German Holstein cows. BMC Genet. 8:62 http://dx.doi.org/10.1186/1471-2156-8-62.

Kühn, C., G. Thaller, A. Winter, O. R. P. Bininda-Emonds, B. Kaupe, G. Erhardt, J. Bennewitz, M. Schwerin, and R. Fries. 2004. Evidence for multiple alleles at the DGAT1 locus better explains a quantitative trait locus with major effect on milk fat content in cattle. Genetics 167:1873-1881.

Meyer, K. 2007. WOMBAT-A tool for mixed model analyses in quantitative genetics by REML. J. Zhejiang Univ. Sci. B 8:815-821. http://dx.doi.org/10.1631/jzus.2007.B0815.

Riquet, J., W. Coppieters, N. Cambisano, J.-J. Arranz, P. Berzi, S. Davis, B. Grisart, F. Farnir, L. Karim, M. Mni, P. Simon, J. F. Taylor, P. Vanmanshoven, D. Wagenaar, J. Womack, and M. Georges. 1999. Identity-by-descent fine-mapping of QTL in outbred populations: Application to milk production in dairy cattle. Proc. Natl. Acad. Sci. USA 96:9252-9257.

Sanger, F., S. Nicklen, and A. R. Coulson. 1977. DNA sequencing with chain-terminating inhibitors. Proc. Natl. Acad. Sci. USA 74:5463-5467.
Seno, L. O., V. L. Cardoso, and H. Tonhati. 2006. Responses to selection for milk traits in dairy buffaloes. Genet. Mol. Res. 5:790-796.

Seno, L. O., V. L. Cardoso, and H. Tonhati. 2007. Economic values for milk production traits of dairy buffaloes in São Paulo State. Rev. Bras. Zootec. 36:2016-2022.

Tonhati, H., M. F. Cerón-Muñoz, J. A. de Oliveira, J. M. C. Duarte, T. P. Furtado, and S. P. Tseimazides. 2000. Genetic parameters of milk production, fat and protein contents in buffalo milk. Rev. Bras. Zootec. 29:2051-2056.

Venables, W. N., and B. D. Ripley. 2002. Modern Applied Statistics with S. 4th ed. Springer, New York, NY.

Yuan, J., J. Zhou, X. Deng, X. Hu, and N. Li. 2007. Molecular cloning and single nucleotide polymorphism detection of buffalo DGAT gene. Biochem. Genet. 45:611-621. 